\title{
REVIEW
}

\section{Management of gastrointestinal haemorrhage}

\section{S Ghosh, D Watts, M Kinnear}

Postgrad Med J 2002;78:4-14

A variety of endoscopic haemostatic techniques have enabled major advances in the management of not only bleeding peptic ulcers and bleeding varices, but also in a variety of bleeding lesions in the small intestine and in the colon. Indeed, the development and widespread implementation of endoscopic haemostasis has been one of the most important developments in clinical gastroenterology in the past two decades. An increasingly ageing cohort of patients with multiple co-morbidity are being treated and therefore improving the outcome of gastrointestinal bleeding continues to pose major challenges.

See end of article for authors' affiliations

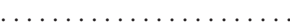

Correspondence to: Dr Subrata Ghosh, Western General Hospital, Edinburgh EH4 2XU, UK: sg@srv0.med.ed.ac.uk

Submitted 14 June 2001 Accepted 21 August 2001
G astrointestinal haemorrhage is one of the most common medical emergencies. All medical and general surgical units need to be familiar with the efficient management of gastrointestinal haemorrhage, and close collaboration between medical and surgical teams is essential. There is some evidence that management is best undertaken in a specialised area according to agreed protocols and guidelines. A multidisciplinary clinical care pathway may improve the efficiency of care for patients with acute upper or lower gastrointestinal haemorrhage. ${ }^{1}$ In addition, trained endoscopy assistants, interventional radiologists, and intensivists are all important team members in managing patients with severe haemorrhage.

In this article, the management of gastrointestinal haemorrhage is discussed with special emphasis on the site of haemorrhage and the underlying diagnosis. The diagnostic approach as well as therapeutic intervention depends on the site of haemorrhage, the rapidity of blood loss, and the nature of the bleeding lesion. A preliminary clue to the site of haemorrhage is the presence of haematemesis and increase of blood urea nitrogen (upper gastrointestinal), or the presence of rectal bleeding (colonic). It has been suggested that a pocket gastrointestinal colour confirmation card to corroborate the patient's history may be useful in directing subsequent investigations. ${ }^{2}$ Insertion of nasogastric tube and aspiration may be helpful in localisation of bleeding and demonstration of rebleeding, but can be misleading. It is poorly tolerated by patients and rarely used in UK practice. Though appropriately timed surgical intervention is an integral part of management of gastrointestinal haemorrhage, details of surgical management are beyond the scope of this review.

\section{RESUSCITATION}

In any patient with a significant gastrointestinal haemorrhage, history taking, physical examination, and resuscitation need to proceed simultaneously. An immediate assessment of haemodynamic status and red cell transfusion requirements must be made, including vital signs in the supine, sitting and, where appropriate, in the standing position. Hypotensive patients require to be placed in a head-down position to aid cerebral perfusion. The supine position should generally be avoided while resuscitating, as this risks pulmonary aspiration. Supplemental oxygen may help a confused, agitated elderly patient with poor cerebral perfusion. Central venous pressure (CVP) monitoring is desirable in patients with organ failure requiring blood transfusion or those with profound shock. CVP monitoring is especially valuable in monitoring elderly patients with severe cardiovascular disease, and guides fluid replacement. An unexpected drop in CVP may also indicate rebleeding. A full blood count, blood urea and creatinine, prothrombin time, activated partial thromboplastin time, type, and cross match should be obtained in all patients urgently. In haemodynamically compromised patients intravenous infusion of normal saline should be started while red cells are being cross matched. The crystalloid versus colloid controversy continues and methodological limitations of the trials preclude any definite evidence based clinical recommendation. Given the lack of evidence in favour of colloids, crystalloids are the convenient and inexpensive choice for fluid resuscitation. The evidence to guide red cell transfusion is limited. A randomised study found more rebleeding in patients transfused early, but this study is small. ${ }^{3}$ Patients with sustained brisk bleeding should of course be transfused urgently to prevent catastrophic exsanguination. If the haemoglobin concentration is less than $100 \mathrm{~g} / \mathrm{l}$ in a patient with postural hypotension, it may be sensible to transfuse, as the haemoglobin will continue to drift downwards after crystalloid infusion. Patients with cardiovascular disease and symptoms such as angina should be transfused to maintain a haemoglobin above $100 \mathrm{~g} / \mathrm{l}$. In all other situations, blood transfusion may be safely withheld till the haemoglobin is less than $70-80 \mathrm{~g} / \mathrm{l}$. The issue about coronary artery disease and electrocardiography is discussed later. Chest radiography is optional but a baseline radiograph may help assessment if the patient later develops symptoms suggestive of pulmonary aspiration.

Abbreviations: COX-2, cyclo-oxygenase-2; CVP, central venous pressure; IDA, iron deficiency anaemia; NSAIDs, non-steroidal anti-inflammatory drugs 
Box 1: Causes of acute upper gastrointestinal haemorrhage

- Peptic ulcer disease.

- Oesophageal/gastric varices.

- Haemorrhagic gastritis.

- Oesophagitis.

- Mallory-Weiss tear.

- Cameron ulcers within hiatus hernia.

- Oesophageal, gastric, duodenal neoplasms.

- Haemobilia.

- Dieulafoy's lesion.

- Aortoenteric fistula.

\section{UPPER GASTROINTESTINAL HAEMORRHAGE}

This is arbitrarily defined as gastrointestinal haemorrhage from a source proximal to the ligament of Treitz. The presentation may be acute with haematemesis and/or melaena or chronic with iron deficiency anaemia as discussed later. The causes of acute upper gastrointestinal haemorrhage to consider at presentation are shown in box 1. Early endoscopy permits accurate risk stratification. Morbidity and mortality are higher in those with rebleeding and $95 \%$ of rebleeding occurs within the first 72 hours of hospitalisation.

\section{Risk stratification}

The risk of death after admission to hospital for acute gastrointestinal bleeding depends on age, the presence of shock, co-morbid conditions, presence of major stigma of recent haemorrhage, and the underlying diagnosis. Based on host factors, patient course, and endoscopic features a number of clinical scoring systems have been devised as predictors of mortality and rebleeding. Rockall et al have incorporated these independent factors into a risk scoring system presented in table $1 .{ }^{4}$ The risk of rebleeding if Rockall risk score equals 0 is
Box 2: Modified Forrest criteria for peptic ulcer haemorrhage

1. Actively bleeding ulcer.

- la. Spurting.

- 1b. Oozing.

2. Non-actively bleeding ulcer.

- 2a. Non-bleeding visible vessel.

- 2b. Ulcer with surface clot.

- 2c. Ulcer with red or dark blue spots.

3. Ulcer with clean base.

around $5 \%$, whereas if the score equals 8 or more the rebleeding rate is over $40 \%$. The mortality rate is below $1 \%$ if the risk score is between $0-2$, whereas with a score of 8 or more the mortality may be as high as $41 \%$.

Endoscopic findings provide the best estimation of the risk of rebleeding. Endoscopic stigma of recent haemorrhage (fig $\mathrm{IA}$ and B) are of prognostic value for rebleeding in case of peptic ulcer bleeding. The modified Forrest criteria (box 2) originally devised in Edinburgh in 1974 is widely used, though even experts can differ in interpretation. ${ }^{6}$

In the presence of shock, an actively bleeding peptic ulcer carries an $80 \%$ risk of further bleeding in hospital. The presence of a non-bleeding visible vessel carries a $50 \%$ risk of further bleeding. The visible vessel represents a pseudoaneurysm of the involved artery, or an adherent blood clot (fig 1B). Patients with an adherent blood clot over an ulcer base are also at considerable risk of further haemorrhage in hospital. Patients with a clean ulcer base or who have black, blue, or red spots rarely rebleed in hospital. Blood flow as measured by Doppler ultrasonography via an endoscope can disagree with endoscopic assessment of stigma of recent haemorrhage. A high false negative and false positive rate for Doppler signals have been demonstrated.

Table 1 The Rockall risk scoring system ${ }^{4}$

\begin{tabular}{|c|c|c|c|c|}
\hline \multirow[b]{2}{*}{ Variable } & \multicolumn{4}{|l|}{ Score } \\
\hline & 0 & 1 & 2 & 3 \\
\hline $\begin{array}{l}\text { Age (years) } \\
\text { Systolic blood pressure (mm Hg) } \\
\text { Pulse (beats/min) }\end{array}$ & $\begin{array}{l}<60 \\
>100 \\
<100\end{array}$ & $\begin{array}{l}60-79 \\
>100 \\
>100\end{array}$ & Crording frilum & \\
\hline Co-morbidity & & & $\begin{array}{l}\text { Cardiac failure, IHD, other major } \\
\text { comorbidity }\end{array}$ & $\begin{array}{l}\text { Renal failure, liver failure, } \\
\text { disseminated malignancy }\end{array}$ \\
\hline Diagnosis & $\begin{array}{l}\text { Mallory-Weiss tear, no SRH, } \\
\text { no lesion }\end{array}$ & All other diagnosis & $\begin{array}{l}\text { Malignancy upper } \\
\text { gastrointestinal tract }\end{array}$ & \\
\hline Stigma of recent haemorrhage & None or dark spot & & $\begin{array}{l}\text { Blood in upper gastrointestinal } \\
\text { tract, adherent clot, visible or } \\
\text { spurting vessel }\end{array}$ & \\
\hline
\end{tabular}

IHD, ischaemic heart disease; SRH, stigma of recent haemorrhage.
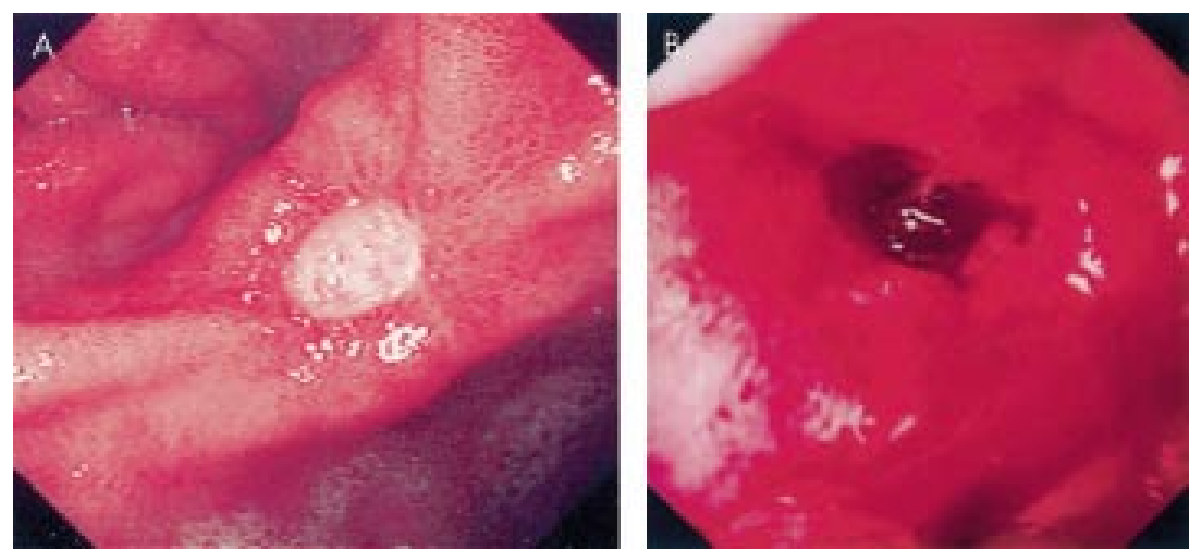

Figure 1 (A) Clean based ulcer at the incisura of the stomach (Forrest 3); (B) visible vessel with some oozing (Forrest 1b). 
Table 2 Methods of endoscopic haemostasis, either singly or in combination

\begin{tabular}{lll}
\hline Injection & Thermal & Mechanical \\
\hline Adrenaline $1: 10000$ or & Heater probe & Haemoclips \\
$1: 100000$ & Bicap probe & $\begin{array}{l}\text { Banding } \\
\text { Fibrin glue }\end{array}$ \\
$\begin{array}{l}\text { Human thrombin } \\
\text { Sclerosants }\end{array}$ & $\begin{array}{l}\text { Gold probe } \\
\text { Argon plasma coagulation }\end{array}$ \\
Alcohol & $\begin{array}{l}\text { Staples/ } \\
\text { sutures }\end{array}$ \\
& Laser therapy & \\
\hline
\end{tabular}

NB. Methods rarely used, less effective, or unsafe are depicted in italics.

\section{Management}

The upper gastrointestinal tract is the commonest source of acute gastrointestinal haemorrhage. The prevalence of upper gastrointestinal bleeding in the population is approximately 100 per 100000 adults per year. ${ }^{8}$ It is important to be able to distinguish between variceal bleeding and non-variceal bleeding as the management strategies are different. Early upper endoscopy in patients hospitalised with upper gastrointestinal haemorrhage results in a shorter hospital stay, reduced risk of recurrent haemorrhage, and reduced requirement for surgical intervention. ${ }^{9}$ In patients with massive bleeding, protection of the airway by placement of a cuffed endotracheal tube by an anaesthetist may prevent aspiration pneumonia during endoscopy.

\section{Non-variceal haemorrhage}

The commonest cause of upper gastrointestinal haemorrhage is peptic ulcer disease, accounting for about $60 \%$ of the source of upper gastrointestinal haemorrhage found at emergency endoscopy. ${ }^{10}$ Approximately $50 \%$ of patients will have a clean based ulcer " (fig 1A) and an uncomplicated presentation requiring no further treatment after endoscopy.

\section{Endoscopic therapy}

In patients with actively bleeding ulcers as well as those with stigma of recent haemorrhage such as visible vessel (fig 1B) or adherent clot, endoscopic therapy will achieve haemostasis in $80 \%$ of patients. Endoscopic therapy might produce impressive haemostasis (fig 2) and more than 50 controlled trials have been published comparing two endoscopic therapies or endoscopic therapy with control patients. Recent systematic reviews have presented the details of these trials and the reader is referred to an excellent analysis of the published evidence. $^{12}$ The trend is towards combination therapy using injection as well as thermal or mechanical therapy. Two metaanalyses have confirmed that endoscopic haemostatic methods lowered the mortality from peptic ulcer bleeding by $30 \%-$ $40 \%{ }^{13}{ }^{14}$ Though these results are impressive, recurrent bleeding after endoscopic haemostasis is not uncommon, occurring in $10 \%-20 \%$ of patients, irrespective of the endoscopic therapeutic modality. In patients who fail initial endoscopic therapy, Rutgeerts et al conducted a large $(\mathrm{n}=854)$ randomised European trial of three different endoscopic injection therapies: (a) single injection of polidocanol (a sclerosing agent); (b) single application of fibrin glue; (c) multiple applications of fibrin glue. ${ }^{15}$ In patients receiving repeated multiple fibrin glue applications, the overall failure rate was nearly halved $(7.7 \%)$ compared with polidocanol injections (13\%) or single fibrin glue applications (12.4\%). In patients with actively bleeding ulcers, the recurrent bleeding was only $15 \%$ in the multiple fibrin glue group compared with recurrent bleeding in others $(42 \%)$. The efficacy of vessel obliteration might be crucially important with thermal methods or sclerosant injection being limited by the extent of tissue injury on

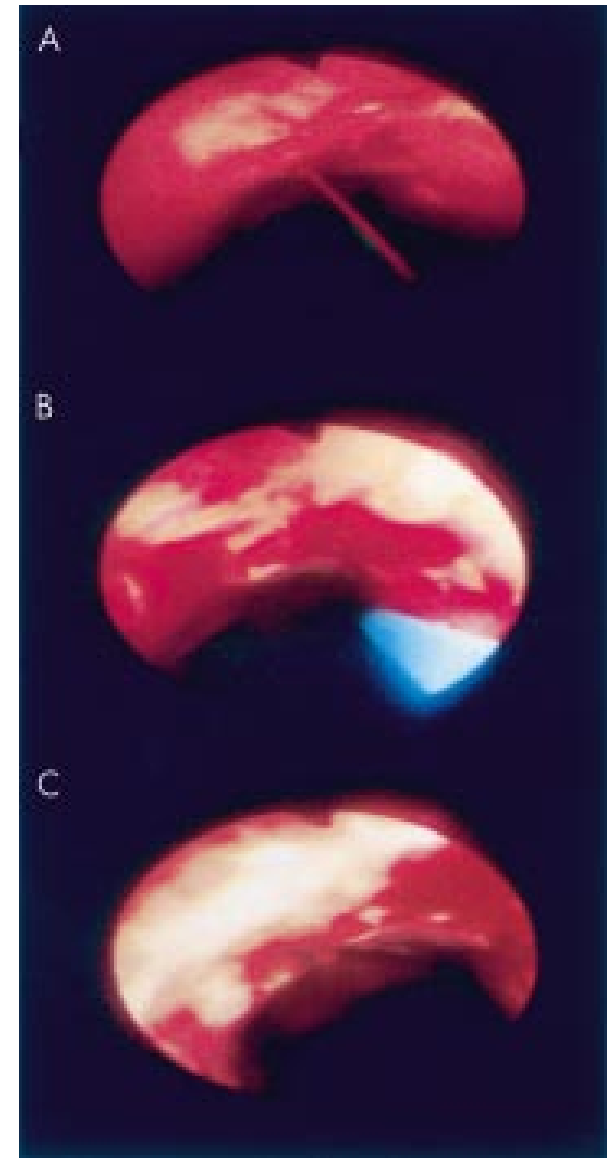

Figure 2 (A) Active arterial haemorrhage (Forrest la), (B) treated with heater probe, and (C) with immediate haemostasis.

repeated applications, while repeated fibrin glue application has a low potential for tissue damage. Another technique is mechanical haemostasis by the use of haemoclips. Adrenaline injection alone compared with the use of adrenaline injection and endoscopic haemoclip placement were found to be equivalent in a non-randomised, but reasonably well matched study including bleeding or recently bled peptic ulcers; there was a trend towards increased effectiveness of combination therapy in actively oozing peptic ulcers. ${ }^{16}$ In a randomised trial of endoscopic application of heater probe compared with haemoclips showed significantly lower rebleeding, transfusion requirements, and hospital stay in the latter group. Most haemoclips spontaneously dislodged within eight weeks of application. ${ }^{17}$ Despite improvements in haemoclip design, these clips can be very difficult to apply in deformed duodenal cap with active haemorrhage, and haemoclip application is unlikely to become an attractive therapeutic option for bleeding duodenal ulcers. Haemoclips may be a particularly attractive option in bleeding from the thin walled oesophagus. The various options of endoscopic haemostasis are presented in table 2 .

\section{Pharmacological treatment}

High dose intravenous omeprazole, $80 \mathrm{mg}$ bolus followed by 8 $\mathrm{mg} /$ hour, after endoscopic treatment of bleeding peptic ulcers has shown a reduction in rebleeding, as well as a reduction in the need for endoscopic retreatment and surgery. ${ }^{18}{ }^{19}$ Mucosal fibrinolytic activity is enhanced in patients with bleeding gastroduodenal ulcers. Acid suppressive therapy decreases this increased fibrinolytic activity, which may be one of the mechanisms explaining the potential beneficial effect of 


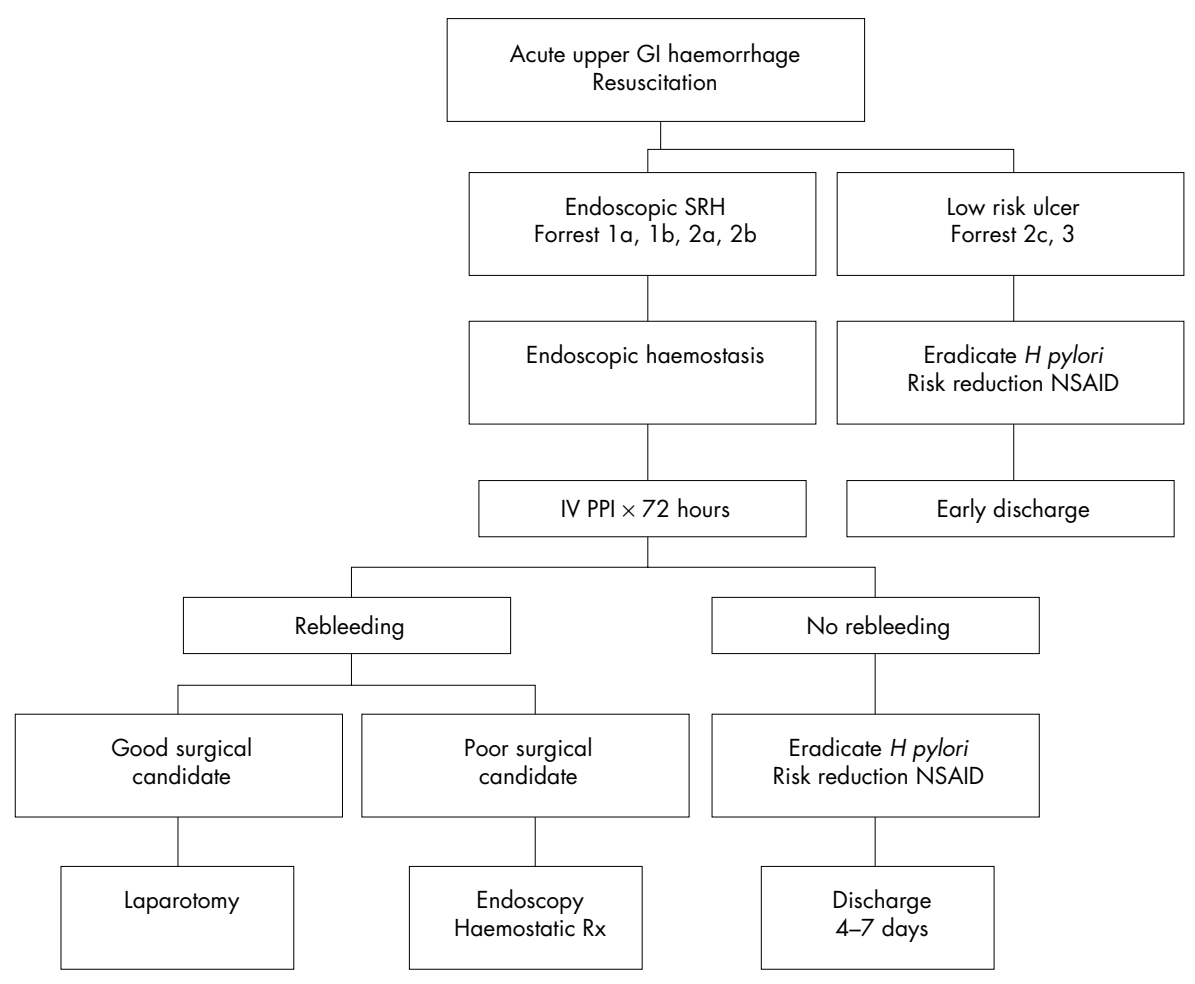

Figure 3 An algorithm for management of acute upper gastrointestinal haemorrhage $(\mathrm{Gl}$ gastrointestinal; IV, intravenous: NSAID, non-steroidal anti-inflammatory drug; PPI, proton pump inhibitor; Rx, therapy; SRH, stigma of recent haemorrhage).

intravenous omeprazole..$^{20}$ Intravenous proton pump inhibitors should be administered to patients with peptic ulcers associated with stigma of recent haemorrhage treated endoscopically, and not to patients with clean based ulcers. Use of intravenous $\mathrm{H}_{2}$-receptor antagonists in this setting however is poorly supported by outcome data of trials. A strategy algorithm for management of acute upper gastrointestinal haemorrhage due to peptic ulcer is presented in fig 3.

Management of recurrent haemorrhage and outcome Repeated endoscopic haemostatic therapy may be applied in case of recurrent haemorrhage, though in a young fit person, surgery is preferable. Recurrent haemorrhage after initial endoscopic haemostasis may also be reduced by a second look endoscopy 24 hours after initial haemostasis. ${ }^{21}$ The technique of endoscopic haemostasis might also influence the rate of rebleeding. Combination therapy with adrenaline injection and thermocoagulation showed a trend towards decreased rebleeding compared with injection therapy alone when dealing with spurting peptic ulcer haemorrhage. ${ }^{22}$ The technique and adequacy of heater probe application might also be important. In vitro studies have reported that at a power setting of $30 \mathrm{~J}$, at least four pulses are required to seal a $1 \mathrm{~mm}$ artery and six pulses to seal larger arteries. ${ }^{23}$

Bleeding ceases spontaneously in about $80 \%$ of patients, but the mortality of at least $6 \%-7 \%$, often approximately $10 \%$, has not decreased in the past 30 years. This disappointing statistic is due to the fact that patients presenting with upper gastrointestinal bleeding belong to an increasingly higher risk group (increasing age and co-morbidity), as well as the fact that newer endoscopic haemostatic therapies, carried out by experienced operators, are not universally practised in real life. ${ }^{24}$ Improved survival from advances in resuscitation and endoscopic treatment has been offset by an increasing number of elderly high risk patients who comprise an increasing proportion of deaths from gastrointestinal haemorrhage. In a UK national audit of acute upper gastrointestinal haemorrhage, the mortality rate in the entire population was $14 \%$, but only $0.6 \%$ for those younger than 60 years without co-morbidity. Most deaths were in elderly patients with considerable co-morbidity. ${ }^{25}$
Role of Helicobacter pylori eradication

In patients with bleeding peptic ulcer associated with $H$ pylori, eradication should be confirmed by urea breath test or the biopsy urease test at endoscopy. The sensitivity of the biopsy urease test decreases in the presence of blood in the antrum. Eradication of $H$ pylori in patients with bleeding ulcers is known to reduce the recurrence of bleeding but the long term efficacy is less clear. In a small study Graham et al followed up 31 patients with major gastrointestinal bleeding from peptic ulcer for a period of 16 weeks. ${ }^{26}$ Rebleeding occurred more often in those who did not receive eradication therapy $(p=0.031)$. Labenz et al prospectively followed up 66 patients who were positive for $H$ pylori and had peptic ulcer bleeding, of whom 42 had successful eradication, for a median of 17 months. ${ }^{27}$ Eradication was associated with statistically significant reductions in both ulcer relapse and bleeding relapse. A longer study by Macri et al evaluated the rate of duodenal ulcer rebleeding after 48 months in 32 patients who received eradication therapy for bleeding duodenal ulcer. ${ }^{28}$ Although all the ulcers healed, successful eradication was achieved in only 21 patients. Rebleeding occurred in eight of the 11 infected patients and in none of those who had succesful eradication $(p=0.002)$.

\section{Mallory-Weiss tears}

Mallory-Weiss tears at the gastric cardia result in upper gastrointestinal haemorrhage. The initiating factor is often persistent retching and vomiting often after alcohol abuse. This is not an uncommon cause of gastrointestinal bleeding and occurs in $5 \%-11 \%$ of all upper gastrointestinal haemorrhages. ${ }^{29}{ }^{30}$ In most cases, haemorrhage from MalloryWeiss syndrome ceases spontaneously and conservative management is sufficient. However, $14 \%-30 \%$ of patients require therapeutic approaches such as endoscopic injection or thermal therapy, ${ }^{31}$ balloon tamponade, ${ }^{32}$ arterial embolisation, or even surgery; endoscopic haemoclipping might be a safe and effective technique to achieve endoscopic haemostasis in this situation. ${ }^{33}$

\section{Variceal haemorrhage}

About one third of patients with varices will have a significant upper gastrointestinal bleeding from varices. Variceal bleeding 


\section{Box 3: Causes of small intestinal haemorrhage}

Vascular lesions

- Vascular ectasias (angiodysplasia)

- Telangiectasia.

- Haemangioma

- Arteriovenous malformation.

- Calibre persistent artery (Dieulafoy's lesion).

Ulceration

- Crohn's disease.

- Non-steroidal anti-inflammatory drugs, potassium, 6-mercaptopurine.

- Meckel's diverticulum.

- Zollinger-Ellison syndrome.

- Vasculitis.

Small intestinal tumours

- Gastrointestinal stromal tumours.

- Lymphoma.

- Carcinoid.

- Small bowel carcinoma

Aortoenteric fistula

Jejunal diverticula

might be suspected if the patient is known to have chronic liver disease or if clinical examination reveals stigma of chronic liver disease. Raised bilirubin, abnormal liver enzymes, low albumin, or a prolonged prothrombin time should also raise the suspicion of variceal haemorrhage. Suspicion of variceal haemorrhage should always lead to emergency endoscopy after resuscitation of the patient. Management of variceal haemorrhage has recently been reviewed in this journal and the reader is referred to it for further details. ${ }^{34}$

\section{SMALL INTESTINAL HAEMORRHAGE}

The small intestine between the second part of the duodenum and the ileocaecal valve is an uncommon site of haemorrhage. Of all patients with gastrointestinal haemorrhage, 3\%-5\% originate from the small intestine. The small intestine is a difficult location to diagnose the source of haemorrhage. Many of these patients present with prolonged undiagnosed iron deficiency anaemia or recurrent episodes of melaena with normal upper endoscopy and normal colonoscopy. An early diagnosis of the bleeding source is distinctly unusual. The common causes of small intestinal haemorrhage are summarised in box 3.

\section{Diagnosis and treatment}

In patients with brisk bleeding, diagnostic approaches are generally combined with potential therapeutic measures. In patients presenting with iron deficiency anaemia, the management strategy is different, as described below. Once upper endoscopy and colonoscopy are negative, the small bowel should be considered as the likeliest source of haemorrhage and push enteroscopy should be considered. Most of the delay is caused by repeated negative upper endoscopies and colonoscopies. It is worth remembering that push enteroscopy not uncommonly detects lesions in the oesophagus, stomach, or duodenum proximal to the ligament of Treitz overlooked at previous upper endoscopies, and hence careful inspection of these areas at enteroscopy is warranted. In patients younger than 50 years, small bowel tumours are the commonest cause (fig 4). Detection of a bleeding small bowel tumour in a young patient should lead to surgery, but marking of the tumour with India ink tattooing to aid the surgeon should be considered if the tumour if distal to the duodenum. In patients older than 60 years, the commonest cause of small intestinal bleeding is angiodysplasia (fig 5A). Push enteroscopy in these patients may be therapeutic in addition to establishing the diagnosis. Bipolar coagulation may be carried out through the enteroscope (fig 5B), and haemostasis achieved in $73 \%$ of the

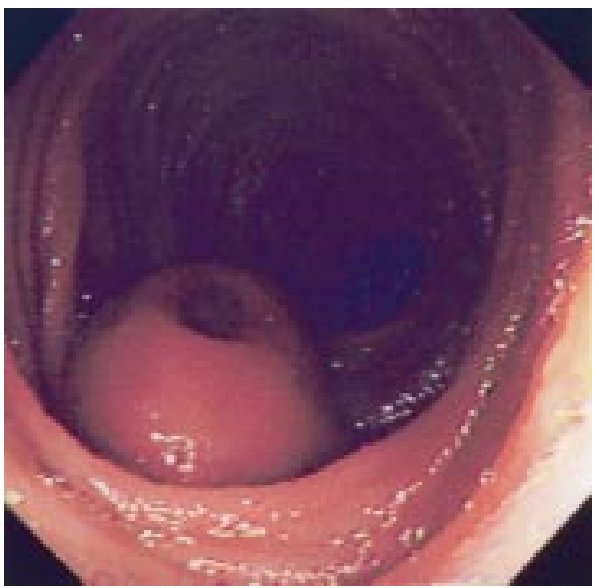

Figure 4 Small bowel stromal tumour (previously called leiomyoma) with central ulceration causing haemorrhage and anaemia, detected at push enteroscopy; this was excised surgically.

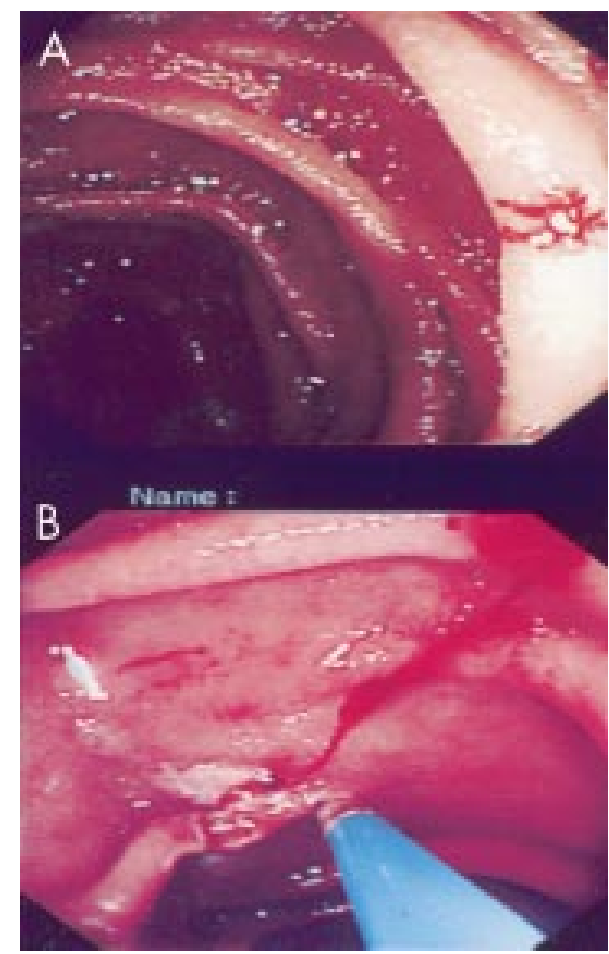

Figure 5 (A) Small intestinal vascular lesion detected at enteroscopy and (B) treated by thermocoagulation.

patients. ${ }^{35}$ The small intestinal wall is thin and laser therapy may be hazardous. The length of the scope makes insertion of other devices such as a heater probe more difficult. Long term (30 months) follow up of 55 patients who had jejunal angiodysplasias cauterised at push enteroscopy confirmed significant reduction of transfusion requirements. ${ }^{36}$

The diagnostic yield of push enteroscopy may be as high as $64 \%$, especially when the new longer push enteroscopes (200$250 \mathrm{~cm}$ ) are used with an overtube ${ }^{37}$ The diagnostic yield is lower $(13 \%-38 \%)$ if an adult or paediatric colonoscope is used. ${ }^{35} 38$

The further one looks into the small bowel, the higher is the diagnostic yield. Sonde enteroscopy relies on peristalsis to propel a long flexible endoscope to the distal small bowel; the ileum is reached in $75 \%$ of examinations, but the ileocaecal valve is reached in only $10 \%$ of cases. ${ }^{39}$ Sonde enteroscopy is not commonly used to investigate small bowel haemorrhage as it 
is a prolonged procedure (6-8 hours or even longer) with no therapeutic capability. Even in best hands, only $50 \%-70 \%$ of the small bowel mucosa maybe visualised. It is possible that capsule enteroscopy will replace sonde enteroscopy in future. Intraoperative enteroscopy is currently the most widely used diagnostic method if push enteroscopy fails to identify a source of bleeding. In this situation, intraoperative enteroscopy is successful in identifying the source of haemorrhage in $83 \%-100 \%$ of patients, ${ }^{40}{ }^{41}$ and angiodysplasias are the commonest cause of bleeding identified..$^{42}{ }^{43}$ The ileocaecal valve or distal ileum within two feet of the valve could be reached at intraoperative enteroscopy on $75 \%$ of occasions. ${ }^{44}$ Adhesions from previous laparotomy might make intubation difficult. Pleating of the small intestine over the endoscope causes mucosal lacerations, and careful observation at insertion is important. Perforations may occur in $5 \%{ }^{44}$ and prolonged ileus may complicate postoperative recovery. ${ }^{45}$ Either endoscopic thermal haemostasis or definitive resection may be carried out at intraoperative enteroscopy. Brisk bleeding during the procedure may obscure the view and give rise to difficulties in achieving haemostasis.

In patients with active bleeding $(0.5-1.0 \mathrm{ml} / \mathrm{min})$, mesenteric angiography can localise the site of small bowel bleeding in $50 \%-72 \%$ of patients, but the diagnostic yield drops if active bleeding has slowed or stopped. ${ }^{46}$ Non-bleeding lesions such as small bowel tumours and angiodysplasias can however be diagnosed. Diagnosis of small intestinal angiodysplasias is more difficult than colonic angiodysplasias as the small bowel mesenteric arteriolar arcades make angiographic interpretation difficult. A positive angiography might lead to surgery or an immediate therapeutic intervention using embolisation with metal microcoils or gelfoam. Intra-arterial vasopressin at angiography has a high haemostatic rate, but unfortunately, the rebleeding rate is also high. Helical computer tomographic angiography involves injection of a contrast agent intra-arterially just before helical computer tomography. A bleeding site was diagnosed in $72 \%$ of a small series of patients, but direct comparison with conventional mesenteric angiography is not available. ${ }^{47}$ Helical computer tomographic angiography is time consuming and not readily available in most UK NHS hospitals.

Radioisotope bleeding scans using ${ }^{99 \mathrm{~m}} \mathrm{Tc}$-radionuclide tagged red cells is readily available, low in cost, and free of complications. Small bowel bleeding is recognised on radionuclide scans by a serpiginous route through the gut by the labelled red cells. Accurate localisation of the site of bleeding however is impossible, even if the small bowel is identified as the source of bleeding. The effectiveness of radioisotope scanning is unclear as most studies address colonic sites of bleeding. Both false positives and false negatives are expected. Delayed scans after injection of radionuclide tagged red cells may yield misleading results. There is no therapeutic potential of radionuclide scans. In a study on 103 patients, radionuclide scans failed to localise bleeding in $85 \%$ of patients, and radioisotope scans are unlikely to be a useful diagnostic step in the management of small intestinal haemorrhage. ${ }^{48}$

Exploratory surgery for recurrent small intestinal bleeding has a low success rate and cannot be recommended, unless on table enteroscopy is also planned. Unlike the colon, long lengths of small bowel cannot be resected without considerable long term morbidity.

\section{ACUTE COLONIC HAEMORRHAGE}

Lower intestinal haemorrhage originates from the colon or the distal ileum. The exact incidence is difficult to assess, as a standard definition of lower intestinal haemorrhage is unavailable. The incidence is generally 20-30 cases/100 000 population and $20 \%-33 \%$ of all haemorrhages from the gastrointestinal tract are from the lower intestinal tract (box $4)$. Acute colonic haemorrhage is suspected when there is

\section{Box 4: Causes of colonic haemorrhage}

- Diverticular disease.

- Colonic angiodysplasia.

- Colonic carcinoma.

- Colonic polyps.

- Colitis: ulcerative colitis, Crohn's colitis, infectious colitis.

- Ischaemic colopathy.

- Other vascular lesions.

- Post-polypectomy haemorrhage.

substantial fresh rectal bleeding, or when there is melaena and upper endoscopy is normal. Unprepared rigid sigmoidoscopy is rarely useful, unless a large rectal tumour is present. In most ambulatory patients complaining of fresh rectal bleeding, the bleeding stops spontaneously after which diagnostic evaluation may be carried out. In 15\% of lower intestinal haemorrhage the bleeding continues and can be massive. Angiodysplasia and colonic diverticula are the commonest causes of colonic haemorrhage and therefore the incidence increases with increasing age. The mortality is lower than in upper gastrointestinal haemorrhage and generally less than $5 \%$.

The value of therapeutic colonoscopy in the setting of acute colonic haemorrhage remains uncertain. Recently, Jensen et al reported their experience in acute colonic diverticular haemorrhage. ${ }^{49}$ In a mixed group of historical controls and patients who received colonoscopic haemostatic treatment, nine out of 17 patients with definite signs of acute diverticular haemorrhage who had diagnostic colonoscopy alone rebled and six out of these nine underwent hemicolectomy. In contrast, 10/48 patients with definite signs of diverticular haemorrhage received colonoscopic haemostatic therapy with injection of adrenaline or bipolar coagulation, and none rebled or required surgery. All patients underwent urgent colonoscopy within 12 hours of admission with full bowel preparation. Though further corroboration from larger controlled studies are required, this study shows the value of early colonoscopy in well prepared colons when colonic haemorrhage is being investigated. However, most departments will have considerable problem in coping with the logistics. Identification of a definite visible vessel within a colonic diverticulum is generally quite unusual if colonoscopy is performed electively after 24 hours from the onset of haemorrhage.

Colonic angiodysplasias are usually found in the right colon. Bleeding from angiodysplasias is usually self limited and intermittent and often presents as chronic iron deficiency anaemia (see below). Bipolar probe coagulation, argon plasma coagulation, or laser therapy may be used to ablate angiodysplastic lesions (fig 6). Perforation, delayed haemorrhage, and post-coagulation syndrome (self limited abdominal pain and peritonism caused by serosal burns) may complicate ablation of vascular lesions.

Colonic tumours rarely present with severe bleeding. Endoscopic therapy (laser, bipolar probe) may be applied for a focal bleeding site. Clearly, surgical resection of the tumour is the definitive therapy.

Colonoscopy in patients with active bleeding is difficult and lesions might be missed in unprepared colon because of poor preparation and active bleeding. Though blood purges, unprepared colonoscopy is difficult and identification of a bleeding lesion usually requires formal bowel preparation. However, patients with massive lower gastrointestinal bleeding generally require emergency mesenteric angiography to localise and control the bleeding site. The superior mesenteric artery angiogram is first obtained as the right colon is a common site of lower gastrointestinal haemorrhage. The choice of investigation often depends on local experience and expertise (table 3 ). 


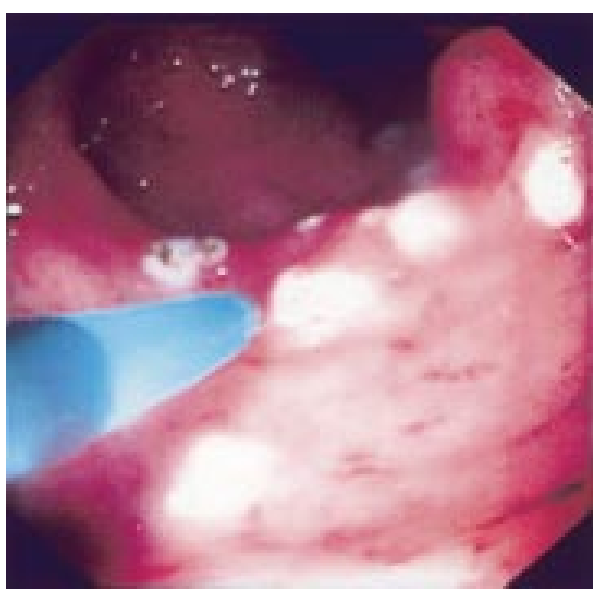

Figure 6 Angiodysplasia of the caecum treated by argon plasma coagulation.

Table 3 Investigative options in lower intestinal haemorrhage

\begin{tabular}{ll}
\hline Investigation & $\begin{array}{l}\text { Rate of bleeding for } \\
\text { optimum detection }\end{array}$ \\
\hline Tagged red cell scanning & $0.1 \mathrm{ml} / \mathrm{min}$ \\
Mesenteric angiography & $1.0 \mathrm{ml} / \mathrm{min}$ \\
Non-selective aortic angiography & $6 \mathrm{ml} / \mathrm{min}$ \\
Colonoscopy & Any rate \\
Intraoperative endoscopy & Active bleeding
\end{tabular}

Urgent colonoscopy performed by experts after thorough bowel cleansing may detect $80 \%$ of colonic angiodysplasias, whereas the diagnostic yield of angiography might be much lower, even as low as $20 \%{ }^{50}$ To optimise colonoscopic yield, the colon requires to be well prepared, the patient well perfused, and excessive narcotic sedation avoided. Administration of naloxone might help by reversing peripheral vasodilation induced by narcotic analgesia, but generally this is of limited help. Helical computer tomography angiography has been reported to be an useful complementary investigation to diagnose right colonic angiodysplasias, but this technique has no therapeutic potential. ${ }^{51}$ It is important to be aware of the fact that upper gastrointestinal haemorrhage might masquerade as blood per rectum. Figure 7 presents an algorithm for the diagnosis and management of lower intestinal haemorrhage distal to the ligament of Treitz.

\section{CHRONIC GASTROINTESTINAL HAEMORRHAGE}

It is appropriate to consider chronic gastrointestinal haemorrhage, most often presenting as iron deficiency anaemia (IDA) as a separate entity. The pace and strategy of management is quite different from the acute haemorrhages described above.

Securing the diagnosis of chronic bleeding can be more challenging than in the acute bleed since the source of the blood loss may not be overtly gastrointestinal. Chronic occult gastrointestinal bleeding is most frequently suspected on the basis of an IDA. The diagnostic algorithm in those patients presenting with an IDA and no overt extragastrointestinal cause has been a contentious issue but the British Society of Gastroenterology has published pragmatic guidelines that suggest running both upper and lower gastrointestinal investigations concurrently or sequentially should the first prove normal. ${ }^{52}$ Upper gastrointestinal endoscopy reveals a cause in $30 \%-50 \%$ of cases of IDA, ${ }^{53-55}$ although in the elderly lower gastrointestinal investigations are more likely to be diagnostically productive. With the exception of those patients diagnosed with gastric carcinoma or coeliac disease at upper endoscopy, all should go on to have colonoscopy preferably, or barium enema and flexible sigmoidoscopy, since dual pathology occurs in $10 \%-15 \%$ of patients. If gastroscopy, small bowel biopsy and colonoscopy are normal, iron replacement is recommended with three monthly follow up haemoglobin monitoring for one year and again at two years and additional replacement given as necessary if the mean corpuscular volume or haemoglobin falls below normal. Reassuringly, IDA does not return in most patients treated in this way. ${ }^{56}$ If the IDA is transfusion dependent, then enteroscopy may be helpful diagnostically and therapeutically. ${ }^{57}$ Berner et al found a bleeding source in $40 \%$ of a cohort of 545 patients with obscure gastrointestinal bleeding undertaking push or sonde enteroscopy. ${ }^{57}$ Most (77.5\%) were vascular lesions and 15\% small bowel tumours (adenocarcinoma, leiomyoma, and lymphoma being the most common). Small bowel tumours accounted mostly for bleeding in patients under 40 years and vascular lesions largely in those over 50 years. Faecal occult blood testing is so insensitive and non-specific as to render it of little benefit in the investigation of IDA.

\section{MANAGEMENT OF GASTROINTESTINAL HAEMORRHAGE IN SPECIAL SETTINGS \\ Post-endoscopy haemorrhage}

The risk of haemorrhage should be discussed with the patient before obtaining consent, especially for colonoscopic polypectomy, endoscopic sphincterotomy, endoscopic pancreatic pseudocyst drainage, and percutaneous endoscopic gastrostomy.

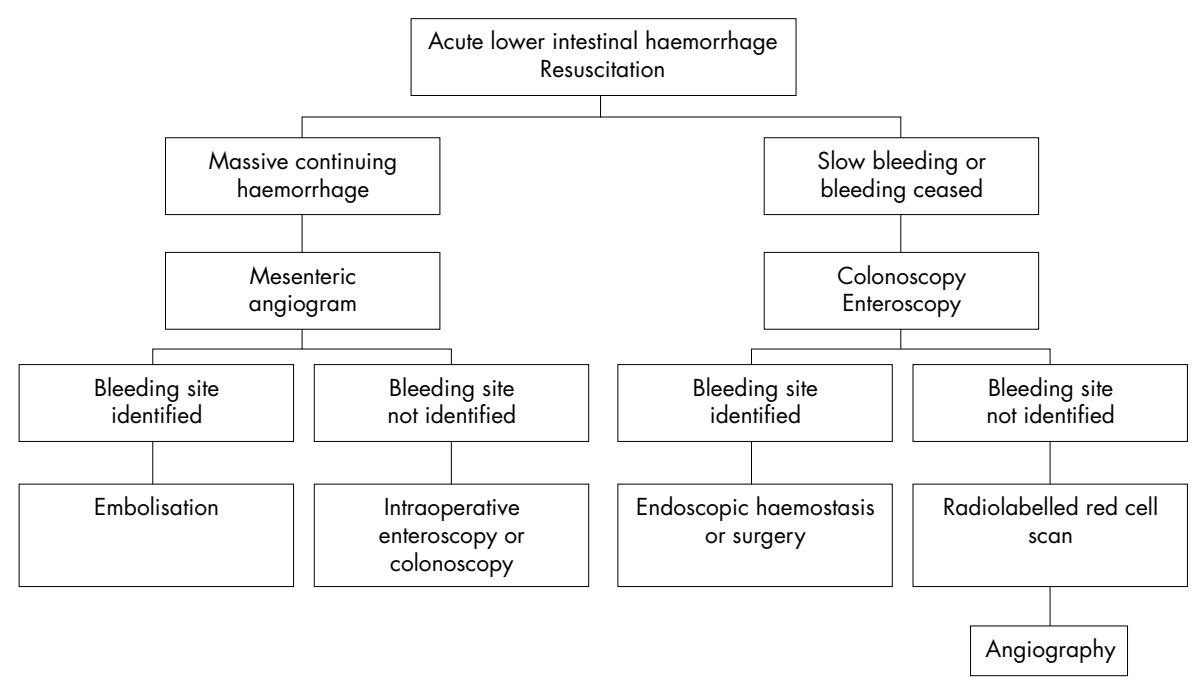

Figure 7 An algorithm for the management of lower intestinal haemorrhage. 


\begin{tabular}{|c|c|c|}
\hline \multirow[t]{2}{*}{ Procedure risk } & \multicolumn{2}{|l|}{ Condition risk for thromboembolism } \\
\hline & High & Low \\
\hline High & $\begin{array}{l}\text { Discontinue warfarin } 3-5 \text { days before procedure. Consider } \\
\text { heparin while INR is below therapeutic level }\end{array}$ & $\begin{array}{l}\text { Discontinue warfarin 3-5 days before procedure. Reinstitute } \\
\text { warfarin after procedure }\end{array}$ \\
\hline Low & \multicolumn{2}{|c|}{ No change in anticoagulation. Elective procedures should be delayed while INR is in supratherapeutic range } \\
\hline \multicolumn{3}{|l|}{ Procedure risk } \\
\hline \multirow[t]{7}{*}{ High risk } & \multicolumn{2}{|l|}{ Polypectomy } \\
\hline & \multicolumn{2}{|l|}{ Biliary sphincterotomy } \\
\hline & \multicolumn{2}{|l|}{ Pneumatic or bougie dilatation } \\
\hline & \multirow{2}{*}{\multicolumn{2}{|c|}{$\begin{array}{l}\text { PEG placement } \\
\text { Endosonography guided FNA }\end{array}$}} \\
\hline & & \\
\hline & \multicolumn{2}{|l|}{ Laser therapy } \\
\hline & \multicolumn{2}{|c|}{ Variceal banding or sclerotherapy } \\
\hline \multirow[t]{4}{*}{ Low risk } & \multirow{2}{*}{\multicolumn{2}{|c|}{$\begin{array}{l}\text { Diagnostic endoscopy, enteroscopy, flexible sigmoidoscopy and colonoscopy with biopsies } \\
\text { Diagnostic ERCP }\end{array}$}} \\
\hline & & \\
\hline & \multirow{2}{*}{\multicolumn{2}{|c|}{$\begin{array}{l}\text { Biliary/pancreatic stent without sphincterotomy } \\
\text { Endosonography without FNA }\end{array}$}} \\
\hline & & \\
\hline \multicolumn{3}{|l|}{ Condition risk } \\
\hline High risk & \multicolumn{2}{|l|}{ Atrial fibrillation associated with valvular heart disease } \\
\hline & \multicolumn{2}{|l|}{ Mechanical mitral valve } \\
\hline & \multicolumn{2}{|l|}{ Mechanical valve and prior thromboembolic event } \\
\hline Low risk & \multicolumn{2}{|l|}{ Deep vein thrombosis } \\
\hline & \multicolumn{2}{|l|}{ Uncomplicated or paroxysmal nonvalvular atrial fibrillation } \\
\hline & \multicolumn{2}{|l|}{ Bioprosthetic valve } \\
\hline & \multicolumn{2}{|l|}{ Mechanical aortic valve } \\
\hline \multicolumn{3}{|c|}{ Aspirin and other NSAID use } \\
\hline In the absen & pre-existing bleeding disorder, endoscopic procedures may $b$ & erformed in patients taking aspirin or other NSAIDs \\
\hline
\end{tabular}

ERCP, endoscopic retrograde cholangiopancreatography; FNA, fine needle aspiration; INR, international normalised ratio; NSAIDs, non-steroidal anti-inflammatory drugs; PEG, percutaneous endoscopic gastrostomy.

\section{Box 5: Average risk of haemorrhage after endoscopic} procedures

- Upper endoscopy: $0.05 \%$

- Percutaneous endoscopic gastrostomy: $0.2 \%-2.5 \%$

- Endoscopic sphincterotomy: $2.5 \%$

- Colonoscopy: 0.02\%

- Colonoscopic polypectomy: $1.6 \%$

- Hot biopsy of colonic polyps: $0.4 \%-1.4 \%$

Anticoagulation should be withheld for these high risk procedures (see table 4 for recommendations).

Coagulation profiles and platelet counts should be obtained before endoscopic sphincterotomy and endoscopic cyst drainage in all cases, and whenever the patient has coagulopathy or risk factors for coagulopathy. Box 5 gives the risk of haemorrhage after endoscopic procedures.

\section{NSAID and gastrointestinal haemorrhage}

Aspirin and other non-steroidal anti-inflammatory drugs (NSAIDs) are major causes of upper gastrointestinal bleeding worldwide. Low dose aspirin doubles the risk of bleeding ulcers, even at doses as low as $75 \mathrm{mg}$ daily. ${ }^{58}$ The use of NSAIDs increases the risk of ulcer complications by a factor of $4 .^{59} \mathrm{~A}$ history of upper gastrointestinal bleeding is a significant risk factor for recurrent bleeding in those taking low dose aspirin or other NSAIDs. ${ }^{60}{ }^{61}$ A study from Hong Kong on 400 patients (250 taking aspirin, 150 taking other NSAIDs) has provided useful guidance on the role of $H$ pylori eradication in patients taking aspirin or other NSAIDs. Among patients with $H$ pylori infection and a history of upper gastrointestinal bleeding who are taking low dose aspirin, the eradication of $H$ pylori is equivalent to treatment with omeprazole in preventing recurrent bleeding. Omeprazole is superior to the eradication of $H$ pylori in preventing recurrent bleeding in patients who are taking other NSAIDs, such as naproxen. ${ }^{62}$

The risk varies with individual NSAIDs ${ }^{61}$ but are similar when equally efficacious doses are used. ${ }^{63}$ Anti-inflammatory selective inhibitors of cyclo-oxygenase-2 (COX-2) can reduce the incidence of gastrointestinal complications. A combined analysis of eight clinical trials in patients with osteoarthritis demonstrated significantly fewer upper gastrointestinal perforations, ulcers and bleeds in patients receiving rofecoxib compared with NSAIDs. ${ }^{64}$ The cumulative incidence of confirmed peptic ulcer bleeds over 12 months was significantly lower with rofecoxib than with NSAIDs $(\mathrm{p}=0.046)$. Two large randomised double blind trials have recently described how selective COX-2 inhibition reduces the incidence of major gastrointestinal complications caused by NSAIDs. ${ }^{656}$ In the CLASS study, $20 \%$ of patients were taking low dose aspirin for prophylaxis against ischaemic heart disease and in this subgroup the incidence of perforation and bleeding was similar to that with NSAIDs. ${ }^{65}$ The risk reduction in the other $80 \%$ of patients was significant and similar to that achieved in the VIGOR study which excluded patients on aspirin. ${ }^{66}$ The results of these studies suggest that COX-2 inhibitors are safer alternatives to conventional NSAIDs in patients who do not require platelet inhibition.

During the year after the launch of rofecoxib in the UK, $12 \%$ of gastrointestinal adverse drug reactions reported to the Committee on Safety of Medicines were associated with upper gastrointestinal perforations, ulceration, and bleeds. In patients with NSAID induced peptic ulcers, continued requirement for NSAIDs would necessitate co-therapy with a proton pump inhibitor. Rates of healing of NSAID associated ulcers is similar with omeprazole and misoprostol but omeprazole is the preferred agent due to lower incidence of side effects and fewer relapses ${ }^{67}$ The ASTRONAUT study showed that omeprazole heals and prevents NSAID associated ulcers more effectively than ranitidine. ${ }^{68}$ Proton pump inhibitors therefore are the treatment of choice when NSAID therapy must be continued.

\section{Gastrointestinal haemorrhage in coronary care/intensive therapy units}

Gastrointestinal bleeding with simultaneous myocardial infarction is not uncommon and frequently overlooked. Cardiac 
Box 6: Commonly unrecognised causes of gastrointestinal haemorrhage

- Gastric Antral Vascular Ectasia (GAVE).

- Cameron lesion(s) within hiatus hernia.

- Dieulafoy's lesion.

- Angiodysplasia.

- Haemobilia.

enzymes are often unchecked even when gastrointestinal haemorrhage requires admission to the intensive care unit. ${ }^{69}$ Severe gastrointestinal haemorrhage may result in haemodynamic compromise, decreased myocardial perfusion and tachycardia associated increased myocardial demand. More uncommonly, myocardial infarction might induce bleeding from intestinal ischaemia as a result of pump failure, or embolisation of left atrial thrombus. A prospective study has reported that $13 \%$ of patients admitted to an intensive care unit for gastrointestinal bleeding had a myocardial infarction. An additional $12 \%$ of patients had evidence of myocardial ischaemia without infarction. ${ }^{70}$ Typical symptoms of myocardial infarction are often absent and gastrointestinal haemorrhage dominates the presentation. Serial electrocardiograms and cardiac enzyme assays should be part of the protocol of management of severe gastrointestinal haemorrhage with haemodynamic compromise. Patients with simultaneous gastrointestinal haemorrhage and myocardial infarction should be managed in the intensive therapy unit, administered supplemental oxygen and transfused to maintain a minimum packed cell volume of 0.30 . Endoscopy may be performed after patient stabilisation with continuous electrocardiogram monitoring, in addition to pulse oximetry and blood pressure monitoring. Endoscopic haemostasis is especially attractive in these patients as surgery has increased mortality in the presence of myocardial infarction. However, clinically unstable patients with hypotension, arrhythmias, angina, or hypoxia are at high risk of endoscopy. The mortality of patients with gastrointestinal bleeding and myocardial infarction is higher than either disease alone. ${ }^{70} 71$

As expected, in critically ill patients admitted to intensive therapy unit with upper gastrointestinal haemorhage, early upper endoscopy is associated with improved outcomes including reduction in intensive therapy unit and hospital stay and recurrent bleeding. ${ }^{72}$ Conversely, inaccurate diagnosis in the intensive therapy unit setting has a significant adverse impact on all outcome measures. It is likely that inaccurate diagnosis is often due to the source of bleeding being concealed by blood clots or fresh blood.

Prevention of stress related gastrointestinal bleeding in critically ill patients is common practice in intensive therapy unit, and $\mathrm{H}_{2}$-receptor antagonists decrease the incidence of bleeding by approximately $50 \% .^{73}$ Though $\mathrm{H}_{2}$-receptor antagonists are commonly used, use of non-acid suppressing agents such as sucralfate has also been recommended to avoid possible nosocomial pneumonia from gastric acid suppression. ${ }^{74}$ The increase in risk of nosocomial pneumonia with gastric acid suppression is, however, controversial.

\section{Obscure gastrointestinal haemorrhage}

This term is generally applied to the situation when an endoscopy and a colonoscopy have failed to reveal the source of haemorrhage. About 3\%-5\% of patients with gastrointestinal bleeding fall in this category. Since enteroscopy with a dedicated push enteroscope or paediatric colonoscope is becoming widely available, a more rigorous application of the term would be a negative push enteroscopy.

A number of lesions are difficult to recognise (box 6), and should be diligently searched for by an experienced endoscopist. The age of the patient is an important consideration
Box 7: Pharmacotherapeutic options to achieve

haemostasis in gastrointestinal haemorrhage

Antifibrinolytics

- Tranexamic acid

- Epsilon-aminocaproic acid (EACA)

Oestrogens

- Low dose.

- High dose.

Danazol

Octreotide

Antiangiogenesis agents

and in patients younger than 50 years, small bowel tumours are common, whereas in patients aged above 50 years angiodysplasias are common.

Tagged red cell scans and mesenteric angiography are often used in this situation, the choice between them being dictated by local expertise and the rate of bleeding (table 3). For uncontrolled obscure haemorrhage, exploratory laparotomy may be required. However any such surgery should be backed up by intraoperative per oral endoscopy or enteroscopy and if required, per anal colonoscopy. Unlike standard endoscopic examinations, careful observation is required on advancement of the scope, as upon withdrawal traumatic lacerations are very common, caused by pleating of the intestine onto the scope. Transillumination by the scope light can be very useful in identifying vascular lesions. On-table mesenteric angiography might also be useful if suitable facilities are available, and if a bleeding source is found, methylene blue injection marks the site of haemorrhage; this is also useful if therapeutic angiography fails to control haemorrhage. Every effort should be made at surgery to localise the site of haemorrhage before directed resection. Blind small bowel resection is definitely undesirable, and subtotal colectomy is associated with poor functional results. In a typical elderly patient with potential colonic haemorrhage, it can be difficult to confidently determine the site of bleeding as both angiodysplasias and diverticular disease are common in this age group.

\section{Pharmacotherapy of gastrointestinal haemorrhage}

This may be tried and indeed may be the only option if there are multiple bleeding lesions, usual vascular, too numerous for endoscopic haemostasis. The agents that might be effective are shown in box 7. Oestrogen preparations are most commonly used $^{75}$ but are associated with significant side effects, both in men and women. Nausea is a very common side effect. Antifibrinolytic agents are also used in these multiple vascular lesions allowing fibrin to close the bleeding sites. ${ }^{76}$

\section{Authors' affiliations}

S Ghosh, D Watts, Gastrointestinal Unit, Department of Medical Sciences, University of Edinburgh, Western General Hospital, Edinburgh, Scotland, UK

M Kinnear, Department of Pharmacy, Western General Hospital, Edinburgh and Department of Pharmaceutical Sciences, University of Strathclyde, Glasgow, Scotland, UK

\section{REFERENCES}

1 Podila PV, Ben-Menachem T, Batra SK, et al. Managing patients with acute, nonvariceal gastrointestinal hemorrhage: development and effectiveness of a clinical care pathway. Am J Gastroenterol $2001 ; 96: 208-19$

2 Zuckerman GR, Trellis DR, Sherman TM, et al. An objective measure of stool color for differentiating upper from lower gastrointestinal bleeding. Dig Dis Sci 1995:40:1614-21.

3 Blair SD, Janvrin SB, McCollum CN, et al. Effect of early blood transfusion on gastrointestinal haemorrhage. Br J Surg 1986;73:783-5. 4 Rockall TA, Logan RFA, Devlin HB, et al. Risk assessment after upper gastrointestinal haemorrhage. Gut 1996;38: 316-21.

5 Forrest JA, Finlayson ND, Shearman DJ. Endoscopy in gastrointestinal bleeding. Lancet 1974;ii:394-7. 
6 Lau JY, Sung JJY, Chan AC, et al. Stigmata of hemorrhage in bleeding peptic ulcers: an interobserver agreement study among international experts. Gastrointest Endosc 1997;46:33-6.

7 Wong RC, Chak A, Kobayashi K, et al. Role of Doppler US in acute peptic ulcer hemorrhage: can it predict failure of endoscopic therapy? Gastrointest Endosc 2000:52:315-21.

8 Longstreth GF. Epidemiology of hospitalization for acute upper gastrointestinal haemorrhage: a population-based study. Am J Gastroenterol 1995;90:206-10

9 Cooper GS, Chak A, Hammar P, et al. Early endoscopy in upper gastrointestinal hemorrhage: associations with recurrent bleeding, surgery and length of hospital stay. Gastrointest Endosc 1999;49: 145-52.

10 Hay JA, Lyubashevsky E, Elashoff J, et al. Upper gastrointestinal haemorrhage clinical guideline-determining the optimal hospital length of stay. Am J Med 1996:100:313-22.

11 Rockall TA, Logan RF, Devlin HB, et al. Selection of patients for early discharge or outpatient care after acute upper gastrointestinal haemorrhage. National Audit of Acute Upper Gastrointestina Haemorrhage. Lancet 1996;347: 1138-40.

12 Church N, Palmer K. Acute non-variceal gastrointestinal hemorrhage: treatment. In: McDonald J, Burroughs A, Feagan B, eds. Evidence based gastroenterology and hepatology. London: BM Books, 1999: 118 - 39

13 Cook DJ, Guyatt GH, Salena BJ, et al. Endoscopic therapy for acute nonvariceal upper gastrointestinal haemorrhage; a meta analysis. Gastroenterology 1992;102:139-48.

14 Sacks HS, Chalmers TC, Blum AL, et al. Endoscopic hemostasis: an effective therapy for bleeding peptic ulcers. JAMA 1990;264:494-9.

15 Rutgeerts P, Rauws E, Wara P, et al. Randomised trial of single and repeated fibrin glue compared with injection of polidocanol in treatment of bleeding peptic ulcer. Lancet 1997:350:692-6.

16 Buffoli F, Graffeo M, Nicosia F, et al. Peptic ulcer bleeding: comparison of two haemostatic procedures. Am J Gastroenterol 2001;96:89-94.

17 Cipolletta L, Bianco MA, Marmo R, et al. Endoclips versus heater probe in preventing early recurrent bleeding from peptic ulcer: a prospective and randomized trial. Gastrointest Endosc 2001:53:147-51.

18 Schaffalitzky de Muckadell OB, Havelund T, Harling $\mathrm{H}$, et al. The effect of omeprazole on the outcome of endoscopically treated bleeding peptic ulcers. A randomized double blind placebo controlled multicenter study. Scand J Gastroenterol 1997;32:320-7.

19 Lau JY, Sung JIY, Lee KK, et al. Effect of intravenous omeprazole on recurrent bleeding after endoscopic treatment of bleeding peptic ulcers. N Engl J Med 2000;343:310-16.

20 Vreeburg EM, Levi $M$, Rauws EAJ, et al. Enhanced mucosal fibrinolytic activity in gastroduodenal ulcer haemorrhage and the beneficial effect of acid suppression. Aliment Pharmacol Ther 2001;15:639-46.

21 Chung SC. Preventing ulcer rebleeding: the role of second-look endoscopy. Can J Gastroenterol 1999;13:409-11.

22 Chung SS, Lau JY, Sung JJ, et al. Randomised comparison between adrenaline injection alone and adrenaline injection plus heat probe treatment for actively bleeding ulcers. BN 1997;314:1307-11.

23 Jensen DM. Heater probe for endoscopic hemostasis of bleeding peptic ulcers. Gastrointest Clin N Am 1991;1:319-39.

24 Chung CS. Surgery and gastrointestinal bleeding. Gastrointest Endosc Clin N Am 1997;7:687-701.

25 Rockall TA, Logan RF, Devlin HB, et al. Incidence of and mortality from acute upper gastrointestinal haemorrhage in the United Kingdom. Steering Committee and members of the National Audit of Acute Upper Gastrointestinal Haemorrhage. BN 1995;311:222-6.

26 Graham DY, Hepps KS, Ramirez FC, et al. Treatment of Helicobacter pylori reduces the rate of rebleeding in peptic ulcer disease. Scand J Gastroenterol 1993;28:939-42.

27 Labenz J, Borsch G. Role of Helicobacter pylori eradication in the prevention of peptic ulcer bleeding relapse. Digestion 1994;55:19-23.

28 Macri G, Milani S, Surrenti E, et al. Eradication of Helicobacter pylori reduces the rate of duodenal ulcer rebleeding: a long-term follow-up study. Am J Gastroenterol 1998;93:925-7.

29 Sugawa C, Benishek D, Walt AJ. Mallory-Weiss syndrome. Am J Surg 1983;145:30-3.

30 Sugawa C, Steffes CP, Nakamura R, et al. Upper Gl bleeding in an urban hospital: etiology, recurrence, and prognosis. Ann Surg 1990;212:521-7.

31 Laine L. Multipolar electrocoagulation in the treatment of active upper gastrointestinal tract hemorrhage: a prospective controlled trial. $N$ Engl J Med 1987;316:1613-17.

32 Welch GH, McArdle CS, Anderson JR. Balloon tamponade for the control of Mallory-Weiss syndrome in patients with coagulation defects. Br J Surg 1987;74:610-11.

33 Yamaguchi $Y$, Yamato T, Katsumi N, et al. Endoscopic hemoclipping for upper Gl bleeding due to Mallory-Weiss syndrome. Gastrointest Endosc 2001;53:427-30.

34 Gow PJ, Chapman RW. Modern management of oesophageal varices. Postgrad Med J 2001;77:75-81.

35 Foutch PG, Sawyer R, Sanowski R. Push-enteroscopy for diagnosis of patients with gastrointestinal bleeding of obscure origin. Gastrointest Endosc 1990;36:337-41.

36 Askin M, Lewis B. Push enteroscopic cauterization: long-term follow-up of 83 patients with bleeding small intestinal angiodysplasia. Gastrointest Endosc 1996; 43:580-3

37 Chong J, Tagle M, Barkin J, et al. Small bowel push-type fiberoptic enteroscopy for patients with occult gastrointestinal bleeding or suspected small small bowel pathology. Am J Gastroenterol 1994;89:2143-6.
38 Messer J, Romeu J, Waye J. The value of proximal jejunoscopy in unexplained gastrointestinal bleeding. Gastrointest Endosc 1984;30:151.

39 Lewis B, Waye J. Total small bowel enteroscopy. Gastrointest Endosc 1987:33:435-8.

40 Mathius-Vliegen E, Tytgat G. Intraoperative endoscopy: technique, indications and results. Gastrointest Endosc 1986;32:381-4.

41 Strodel W, Eckhauser FE, Knol JA, et al. Intra-operative fibreoptic endoscopy. Am Surg 1984;50:340-4.

42 Lau W, Wong S, Yuen W, et al. Intraoperative enteroscopy for bleeding angiodysplasias of the small intestine. Surg Gynaecol Obstet 1989; 168:341-4

43 Desa L, Ohri S, Hutton KA, et al. Role of intraoperative enteroscopy in obscure gatrointestinal bleeding of small bowel origin. Br J Surg 1991;78:192-5.

44 Lewis B, Wenger J, Waye J. Intraoperative enteroscopy versus small bowel enteroscopy in patients with obscure Gl bleeding. Am J Gastroenterol 1991;86:171-4.

45 Whelan R, Buls J, Goldberg S, et al. Intraoperative endoscopy: University of Minnesota experience. Am Surg 1989;55:281-6.

46 Browder W, Cerise E, Litwin M. Impact of emergency angiography in massive lower gastrointestinal bleeding. Ann Surg 1986;204:530-6.

47 Ettorre G, Francioso G, Garribba A, et al. Helical CT angiography in gastrointestinal bleeding of obscure origin. Am J Roentgenol 1997; 168:727-30

48 Voeller G, Bunch G, Britt L. Use of technetium-labelled red blood cell scintigraphy in the detection and management of gastrointestinal haemorrhage. Surgery 1991;110:799-804.

49 Jensen DM, Machicado GA, Jutabha R, et al. Urgent colonoscopy for the diagnosis and treatment of severe diverticular hemorrhage. N Engl J Med 2000;342:78-82.

50 Jensen DM, Machicado GA. Diagnosis and treatment of severe hematochezia: the role of urgent colonoscopy after purge. Gastroenterology 1988;95:1569-74.

51 Junquera $\mathbf{F}$, Quiroga S, Saperas E, et al. Accuracy of helical computed tomographic angiography for the diagnosis of colonic angiodysplasia. Gastroenterology 2000; 1 19:293-9.

52 Goddard AF, Mclntyre AS, Scott BB. Guidelines for the management of iron deficiency anaemia. Gut 2000;46(suppl IV):iv1-5

53 Kepczyk T, Kadakia SC. Prospective evaluation of gastrointestinal tract in patients with iron-deficiency anemia. Dig Dis Sci 1995;40:1283-9.

54 Hardwick RH, Armstrong CP. Synchronous upper and lower gastrointestinal endoscopy is an effective method of investigating iron-deficiency anaemia. Br J Surg 1997;84:1725-8

55 Rockey DC, Cello JP. Evaluation of the gastro-intestinal tract in patients with iron-deficiency anemia. N Engl J Med 1993;329:1691-5.

56 Sahay R, Scott BB. Iron deficiency anaemia-how far to investigate? Gut 1993;34:1427-8

57 Berner JS, Mauer K, Lewis B. Push and sonde enteroscopy in the diagnosis of obscure gastrointestinal bleeding. Am J Gastroenterol 1994;89: 2139-42

58 Weil J, Colin-Jones D, Langman $M$, et al. Prophylactic aspirin and risk of peptic ulcer bleeding. BMU 1995;310:827-30.

59 Hernandez-Diaz S, Rodriguez LA. Association between nonsteroidal anti-inflammatory drugs and upper gastrointestinal tract bleeding/perforation: an overview of epidemiologic studies published in the 1990s. Arch Intern Med 2000;160:2093-9.

60 Lanas A, Bajador E, Serrano P, et al. Nitrovasodilators, low-dose aspirin, other nonsteroidal antiinflammatory drugs, and the risk of upper gastrointestinal bleeding. N Engl J Med 2000;343:834-9.

61 Garcia Rodriguez LA, Jick H. Risk of upper gastrointestinal bleeding and perforation associated with individual non-steroidal anti-inflammatory drugs. Lancet 1994:343:769-72.

62 Chan FKL, Chung SCS, Suen BY, et al. Preventing recurrent upper gastrointestinal bleeding in patients with Helicobacter pylori infection who are taking low-dose aspirin or naproxen. N EnglJ Med 2001;344:967-73

63 Langman MJ, Weil J, Wainwright $P$, et al. Risks of bleeding peptic ulce associated with individual non-steroidal anti-inflammatory drugs. Lancet 1994;343: 1075-8.

64 Langman MJ, Jensen DM, Watson DJ, et al. Adverse upper gastrointestinal effects of rofecoxib compared with NSAIDs. JAMA 1999;282: 1929-33

65 Silverstein FE, Faich G, Goldstein JL, et al. Gastrointestinal toxicity with celecoxib vs nonsteroidal anti-inflammatory drugs for osteoarthritis and rheumatoid arthritis: the CLASS study: a randomized controlled trial. Celecoxib Long-term Arthritis Safety Study. JAMA 2000;284:1247-55.

66 Bombardier C, Laine L, Reicin A, et al. Comparison of upper gastrointestinal toxicity of rofecoxib and naproxen in patients with rheumatoid arthritis. N Engl J Med 2000;343:1520-8.

67 Hawkey CJ, Karrasch JA, Szczepanski L, et al. Omeprazole compared with misoprostol for ulcers associated with nonsteroidal antiinflammatory drugs. N Engl J Med 1998;338:727-34.

68 Yeomans ND, Tulassay Z, Juhasz L, et al. A comparison of omeprazole with ranitidine for ulcers associated with nonsteroidal antiinflammatory drugs. Acid Suppression Trial: Ranitidine versus Omeprazole for NSAID-associated Ulcer Treatment (ASTRONAUT) Study Group. N Engl J Med 1998;338:719-26.

69 Bhatti N, Amoateng-Adjepong Y, Qamar A, et al. Myocardial infarction in critically ill patients presenting with gastrointestinal haemorrhage: retrospective analysis of risks and outcomes. Chest 1998;114:1 137-42.

70 Emenike E, Srivastava S, Amoateng-Adjepong Y, et al. Myocardial infarction complicating gastrointestinal hemorrhage. Mayo Clin Proc 1999;74:235-41 
71 Cappell MS. A study of the syndrome of simultaneous acute upper gastrointestinal bleeding and myocardial infarction in 36 patients. Am J Gastroenterol 1995;90:1444-9.

72 Chak A, Cooper GS, Lynne LE, et al. Effectiveness of endoscopy in patients admitted to the intensive care unit with upper $\mathrm{Gl}$ hemorrhage. Gastrointest Endosc 2001;53:6-13.

73 Cook DJ, Reeve BK, Guyatt GH, et al. Stress ulcer prophylaxis in critically ill patients: resolving discordant meta-analyses. JAMA 1996;275:308-14.
74 Tryba M. Side effects of stress bleeding prophylaxis. Am J Med 1989;86(suppl 6A):85-93.

75 Van Cutsem E, Rutgeerts P, Vantrappen G. Treatment of bleeding gastrointestinal vascular malformations with oestrogen-progesterone. Lancet 1990;335:953-5.

76 Saba H, Morelli G, Logrono L. Brief report: treatment of bleeding in hereditary hemorhagic telangiectasia with aminocaproic acid. N Engl J Med 1994;330:1789-90.

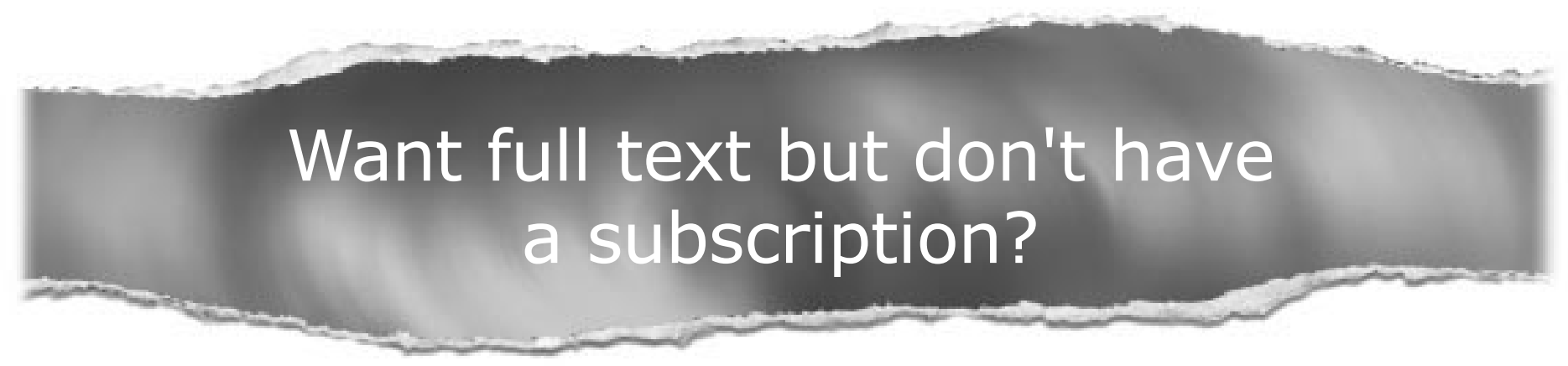

\section{Pay per view}

For just $\$ 8$ you can purchase the full text of individual articles using our secure online ordering service. You will have access to the full text of the relevant article for 48 hours during which time you may download and print the pdf file for personal use.

www.postgradmedj.com 